OPEN ACCESS

Edited by:

Suvi-Maria Katariina Saarelainen, University of Eastern Finland, Finland

Reviewed by:

Paul T. P. Wong

Trent University, Canada

Lluis Oviedo,

Pontifical University Antonianum, Italy

${ }^{*}$ Correspondence:

Lia Araújo

liajaraujo@esev.ipv.pt

Specialty section:

This article was submitted to

Health Psychology,

a section of the journal

Frontiers in Psychology

Received: 17 June 2021

Accepted: 16 August 2021

Published: 10 September 2021

Citation:

Araújo L, Teixeira L, Afonso RM and Ribeiro O (2021) To Live or Die: What

to Wish at 100 Years and Older.

Front. Psychol. 12:726621

doi: $10.3389 /$ fpsyg.2021.726621

\section{To Live or Die: What to Wish at 100 Years and Older}

\author{
Lia Araújo ${ }^{1,2 \star}$, Laetitia Teixeira ${ }^{1,3}$, Rosa Marina Afonso ${ }^{1,4}$ and Oscar Ribeiro ${ }^{1,5}$ \\ ${ }^{1}$ Center for Health Technology and Services Research (CINTESIS), Porto-Aveiro, Portugal, , ${ }^{2}$ Department Psychology and \\ Educational Sciences, School of Education, Polytechnic Institute of Viseu, Viseu, Portugal, ${ }^{3}$ Department of Population \\ Studies, Institute of Biomedical Sciences Abel Salazar, University of Porto, Porto, Portugal, ${ }^{4}$ Department Psychology and \\ Education, University of Beira Interior, Covilhã, Portugal, ${ }^{5}$ Department of Education and Psychology, University of Aveiro, \\ Aveiro, Portugal
}

Previous research has shown that will to live is a strong predictor for survival among older people, irrespective of age, gender, and comorbidities. However, research on whether life at age 100 is perceived as worth living is limited. The available literature has presented evidence for good levels of positive attitudes and life satisfaction at such an advanced age, but it has also suggested that a longing for death is common. This study aimed to add to the existing data on this matter by exploring centenarians' will to live and the associated factors. The sample comprised 121 centenarians (mean age, 101 years; SD, 1.63 years), 19 (15.7\%) of whom were males, from two centenarian studies (PT100). Answers to open questions were analyzed to identify the centenarians' will to live and the reasons behind it. Three groups were created (willing to live longer, not willing to live longer, no clear positioning) and further analyzed in terms of sociodemographic characteristics, health status, social functioning, and well-being. Of the total sample, $31.4 \%$ expressed willingness to live longer, $30.6 \%$ did not, and 38\% presented no clear positioning. The presence of the Catholic religion (God) was referred for centenarians in all three groups. Annoyance, uselessness, loss of meaning, disconnection, and loneliness were the most common justifications for being reluctant to live longer. Positive valuation of life and good self-rated health, followed by having a confidant and reduced pain frequency, were the factors associated with being willing to live longer. The results of the study contribute to the understanding of the psychological functioning of individuals with exceptional longevity, particularly concerning the factors behind willingness to live at such an advanced age.

Keywords: will to live, centenarians, valuation of life, religion, PT100, longevity

\section{INTRODUCTION}

Due to the phenomenon of population aging, the length of human life has become of interest in aging and gerontological research. Particularly in developed countries, reaching 100 years of age is becoming more common (Teixeira et al., 2020), and some individuals, known as supercentenarians, will even live beyond 110 years old. This increase in life expectancy and longevity is the result of significant advances in medical, social, political, economic, and cultural domains that together have improved health, nutrition, and sanitation conditions (Mathers et al., 2015). However, this delay of mortality raises important questions about quality of life in the later years of those who achieve exceptional longevity. Although the general consensus is that living longer will only be desirable if 
lived with meaning, purpose, and good quality of life, the clinical, bioethical, and social implications of extended life expectancy have raised various debates (e.g., Serra et al., 2011).

Research on the desire to reach advanced ages has shown similar results across different age groups and countries. For instance, in a study of 715 university students in Austria, Norway, Poland, and Russia, Bowen et al. (2020) found that $25.8 \%$ of the participants wanted to live 100 or more years, while the great majority $(74.2 \%)$ did not. Of the participants, $21.2 \%$ wanted to live fewer than 80 years, and $53 \%$ wanted to live to their 80 s or 90s. In another study with a larger sample (1631) of young and middle-aged adults in the United States, Bowen and Skirbekk (2017) found that $26.4 \%$ preferred a life expectancy of 100 or more years old, $24.6 \%$ preferred a life expectancy in the 90 s, and $31.9 \%$ preferred a life expectancy in the $80 \mathrm{~s}$.

Age (being older) has been shown to affect people's attitudes toward living an extremely long life (Huohvanainen et al., 2012; Karppinen et al., 2016). When asked about their desire to reach 100 years old, 32.9\% (aged 75-96; Karppinen et al., 2016) and 37.2\% (aged 72-88; Huohvanainen et al., 2012) of communitydwelling older adults from Finland wanted to live to be 100 . Karppinen et al. (2016) also found that gender (male) and subjective health (positive) significantly impacted the desire to live longer. Furthermore, a qualitative analysis of the reasons why the oldest-old participants wanted to live to 100 showed the importance of health and functioning, as many of the participants wished to live longer if they could remain independent-that is, "as long as their health remains good" (Karppinen et al., 2016, p. 547). The participants who wanted to live to 100 also displayed positive attitudes (e.g., curiosity, love of life, belief) and rational reasons for living longer (e.g., significant roles, offspring).

Interestingly, when studying a sample of 115 centenarians' close family members (aged 25-86 years; mean, 64.97), Brandão et al. (2019) found that $56.5 \%$ wanted to reach 100 . Thus, having close contact with a centenarian may have a positive influence on people's attitudes toward living longer. Still, the family members stated that conditional circumstances related to health and caregiving were required to make living to 100 desirable. These included, among others, having good physical health, not being bedridden, being capable of maintaining independence performing activities of daily life (ADL), having the ability to express their wishes (good cognitive status), and having family support and/or someone who provided care in case of dependency, which would allow them to continue living at home. Indeed, research on children's perceptions of challenges relating to the end of life of their centenarian parents showed that it seems to be a potential double confrontation for the offspring who are often old adults themselves, i.e., "some adult children reported that observing the centenarian was like looking into a mirror and a kind of preview of their own possible challenges" (Eggert et al., 2020, p. 7).

In a review of available theoretical and empirical work about motivation for longevity across the life span, Lang and Rupprecht (2019), identified that people have different profiles, which can be divided in three mindsets: (i) an essentialist, based on an infinite life, (ii) a medicalist, appraising aging as being primarily based on quality of health, and (iii) a stoicist mindset that associates longevity and lifetime extension with the experience of grace and meaning. The authors argued that longevity motivation depends of determinants related to context, health functioning, and personal belief systems, that there could be change in longevity motivation over time and that the mindsets have differential behavioral consequences in what ways individuals want to approach old age.

Despite the available literature on the desire to become a centenarian in several populations (e.g., younger adults, centenarians' family members) and longevity extension, whether centenarians themselves still want to live longer remains undetermined, especially since despair, depressive symptoms, and large suicide rates have been documented in this population (Shah et al., 2014). Will to live is an important indicator of well-being that can be perceived as a basic need, a goal, and a drive (Carmel, 2012). Will to live reflects a focus on the present and a person's existential motivation to live (Bornet et al., 2021). Lawton et al. (1999) presented will to live as the most concretely anchored cognitive outcome of a dynamic cognitive-affective thought process in which people weigh a variety of inputs that affect their psychological well-being. It is influenced by external and internal factors and is expressed physiologically, psychologically, and socially (Lawton et al., 1999; Carmel, 2012). Furthermore, will to live has a great association with psychological variables like resilience and life satisfaction (Bornet et al., 2021). Lawton et al. (1999) proposed that years of desired life are mediated by an intervening cognitive-affective schema, which they designated as "valuation of life" (VOL). This schema includes hope, futurity, purpose, meaningfulness, persistence, and self-efficacy as its main core constructs (Lawton et al., 2001). In his well-known Holocaust memoir, Man's Search for Meaning, Frankl (1963) associated will to live with purpose; using Nietzsche's words, he stated that "he who has a why to live for can bear with almost any how” (p. 84).

Although heterogeneity is expected in the functionality of those of advanced age, most centenarians face high constraints in terms of physical, sensory, and cognitive function (Serra et al., 2011). However, many centenarians are still able to maintain good levels of life satisfaction, positive affect, and happiness (Cheng et al., 2021). Psychological strengths, such as optimistic outlook (Jopp and Rott, 2006), positive life attitudes (Wong et al., 2014; Kato et al., 2015; Mackowicz and Wnek-Gozdek, 2016), purpose (Araújo et al., 2016), and existential beliefs (Araújo et al., 2017), may be of particular importance for centenarians' well-being. Additionally, faith and social relationships seem to affect the way centenarians experience and perceive their old age, regardless of personal limitations and differences (Mackowicz and Wnek-Gozdek, 2016). In a study investigating the relationship between meaning in life, will to live, and ageassociated health restrictions (e.g., number of diseases), Jopp et al. (2017) found that both meaning in life and will to live have strong, direct effects on well-being. Health factors were, in comparison, less important or non-significant.

Understanding older adults' will to live is important since they are increasingly aware of the approaching end of life and face cumulative losses in almost all domains of life (Carmel, 2012). Nevertheless, will to live has not been a main focus of research; 
a greater number of studies have investigated attitudes toward death and dying, especially in end of life care. Empirical research of the oldest-old (Fleming et al., 2016) and older adults without a serious medical condition (Van Wijngaarden et al., 2015) is limited. A recent study of German and Portuguese centenarians reported that a notable portion of the participants did not think about the end of their lives; however, most of these centenarians experienced health or social problems (Boerner et al., 2019). This study used both quantitative and qualitative approaches to deepen the available scientific understanding of will to live in extreme longevity and to explore its associated factors.

\section{METHODS}

\section{Data Collection}

The data for this study came from two centenarian studies - the Oporto Centenarian Study (PT100) and the Beira Interior Centenarian Study (PT100 Beira Interior)—which were conducted in two distinct geographical regions of Portugal, each one with an area of $\sim 60 \mathrm{~km}^{2}$. A total of 291 individuals aged 100 years and older between December 2013 and December 2014 were identified through voter registration files, churches, nursing homes, local media newspapers, and snowball sampling. Of the 291 centenarians, 50 were excluded because they died in the interim or because their relatives refused their participation due to advanced dementia, other major health problems, or lack of interest in the study. The 241 participants were interviewed faceto-face, and a sample of 121 centenarians who were not affected by severe cognitive impairment and who answered the questions about their thoughts and own perceptions required for the study were included.

The data were collected during one or two sequential interview sessions either with the centenarian and/or a proxy respondent. Following recommended strategies (Sachdev et al., 2012), age validation was performed by a protocol entailing personal identity document verification (e.g., birth certificate) and milestones assessments (e.g., wedding date, date of firstborn, subsequent birthdates of children). An informed consent previously approved by the National Commission on Data Protection was used. More information about the methodological procedures of both centenarian studies can be found in Ribeiro et al. (2015).

\section{Measures}

\section{Socio-Demographic Characteristics}

The following variables were considered in this set: age, sex (male/female), education (having/not having formal education), and living in an institution (yes/no).

\section{Health Condition}

The following objective and subjective health measures were determined: pain frequency (never, seldom, sometimes, often/always), presence of physical fatigue (yes/no), and selfrated health $(\mathrm{SRH})$. To determine $\mathrm{SRH}$, the following question was asked: "In general, would you say your health is...?" Five response options were given: excellent, very good, good, reasonable, and bad. The responses were scored 1 for a bad SRH,
2 for a reasonable SRH, and 3 for a positive SRH (i.e., excellent, very good, or good).

The total number of self-reported health conditions was obtained from a list of age-related problems commonly observed in the older population, including high blood pressure, a heart condition, diabetes, chronic lung disease, ulcers or other serious stomach issues, cirrhosis or other liver problems, a kidney condition, frequent urinary infections, incontinence, prostate problems, problems with vision or hearing, arthritis, osteoporosis, stroke, cancer, pneumonia, and falls, among others. Functional capacity was assessed through the Older Americans Resources and Services (OARS) Multidimensional Functional Assessment Questionnaires (Fillenbaum and Smyer, 1981). This questionnaire includes seven items that assess basic ADL (e.g., the capacity for walking, bathing, eating, going to the toilet) and seven items to assess instrumental activities of daily living (IADL; e.g., the capacity to use the telephone, go shopping, do housework, prepare meals). The participants were asked to rate how much difficulty they had performing each of these activities on a three-point scale $(2=$ no difficulty; $1=$ can complete the activity with some help; $0=$ cannot complete the activity without help). The seven items of ADL and the seven items of IADL were summed to obtain the total scores of each domain, with a higher score indicating greater independence.

\section{Social Functioning}

The following questions from the Social Resources subscale of the OARS (Fillenbaum and Smyer, 1981) were considered: the number of visits the centenarians had on a regular basis (none; $1-2 ; 3-4 ; 5$ or more), how often the centenarian felt lonely (many times, sometimes, almost never, or never), and the time spent with people the centenarian did not live with (none, once/week, 2-6 times/week, once/day, or more). Four questions from the Lubben Social Network Scale (Lubben, 1988) were also used: the number of relatives and friends that the centenarian saw or heard from at least once a month and the number of relatives and friends that the centenarian has as a confidant, i.e., that could talk to about private matters (none; $1-2 ; 3+$ ).

\section{Well-Being}

The Satisfaction with Life Scale (SWLS; Diener et al., 1985) is a short, five-item instrument that was designed to measure global cognitive judgments of satisfaction with one's life. The format of the questionnaire was modified after reported methodological constraints in assessing centenarians who described their difficulties in understanding self-referent statements and using five or six answering categories (Jopp and Rott, 2006). To avoid these difficulties, the questionnaire was changed from statements to questions, with a response of 0 being no, 1 being in between, and 2 being yes.

The Positive Valuation of Life Scale (Positive VOL; Lawton et al., 2001) is a 13-item scale that was formulated to examine the factors that may influence a person's will to continue to live and affect end-of-life attitudes and behaviors. In the Portuguese version used in this study, two factors were identified: existential beliefs and perceived control (Araújo et al., 2015). The answering format was changed from five to three options $(0=$ no, $1=$ 
in between, and 2 = yes) due specific difficulties in assessing centenarians (see Jopp and Rott, 2006).

\section{Will to Live}

The outcome variable was derived from the qualitative analysis of responses to two open questions (To what age would you like to live? and Do you long for death?). The responses were coded as yes (willing to live longer), no (not willing to live longer), and no indicators of will (without a clear positioning).

\section{Analysis}

The answers given to the questions were audiotaped, transcribed, and subjected to qualitative analysis. The first and last authors carefully read all the transcripts and defined the three major categories of the centenarians' will to live: willing to live longer, unwilling to live longer, and without a clear positioning. Then, the two authors met to match their independent ratings and discuss the differences and interpretations of the data.

In the next phase, the transcripts were examined to identify common themes using open coding, clustering, and theme identification (Hsieh and Shannon, 2005). These themes regarded the common reasons presented for willingness to live longer (or not), as well as the reasons for not presenting a clear positioning. Then, both authors independently analyzed the data and discussed discrepancies until reaching consensus. All answers were carefully reread, and final categorization of the emergent themes was defined (Braun and Clarke, 2006). Final categories were later discussed with the other authors.

Quantitative and descriptive analyses were used to characterize the sample according to sociodemographic characteristics, health status, social functioning, and well-being. To calculate the total score of the scales (e.g., satisfaction with life), the items missing data were replaced, and the mean was considered when at least $50 \%$ of the items were completed. The comparison of groups, which was defined by the outcome "will to live," was performed using a Chi-square test or Fisher's exact test and one-way ANOVA. In all quantitative analyses, a significance level of 0.05 was considered. All analyses were performed in IBM SPSS software (version 26.0).

\section{RESULTS}

\section{Sample Characteristics}

The sample comprised 121 centenarians with an overall mean age of 101 years $(S D=1.5$ years); $19(15.7 \%)$ were male. A majority of the centenarians $(45.5 \%)$ had no formal education, and $40.5 \%$ were institutionalized. Regarding health status, $44.6 \%$ reported that their health was perceived as being "good, very good, or excellent," while $42.6 \%$ reported physical fatigue, and $17.5 \%$ reported never having pain. The mean scores of ADL and IAL were $3.71(S D=3.21)$ and $8.23(S D=4.26)$, respectively. Finally, the average number of diagnoses was $3.26(S D=1.94)$. Concerning social function, $36.2 \%$ of the centenarians had 5 or more visits, $51.0 \%$ reported missing people around them, and $25.7 \%$ never felt alone. The mean score of the SWLS was 6.54 $(S D=1.93)$. The mean scores of the Positive VOL Scale, factor
TABLE 1 | Reasons for willingness to live longer and the number of quotations for each.

\begin{tabular}{ll}
\hline Category $(\boldsymbol{n})^{\mathbf{a}}$ & Examples of quotations \\
\hline God (14) & $\begin{array}{l}\text { I'm ready as soon as God understands [it's } \\
\text { the time], but I want to live at least until I } \\
\text { am } 103 \text { years old. }\end{array}$ \\
$\begin{array}{ll}\text { I would like to see my grandson's } \\
\text { [university] graduation. }\end{array}$ \\
$\begin{array}{ll}\text { Conditional wish: if in the presence of } \\
\text { similar functioning levels and without } \\
\text { being a burden (3) }\end{array}$ & $\begin{array}{l}\text { without being a burden to others or being } \\
\text { bedridden. }\end{array}$ \\
Enjoying living (3) & $\begin{array}{l}\text { Now that the good weather comes } \\
\text { [springtime approaching], I want to live! }\end{array}$ \\
\hline
\end{tabular}

${ }^{a}$ Frequencies were not mutually exclusive.

1 (existential beliefs), and factor 2 (perceived control) were 16.7 $(S D=6.0), 9.39(S D=3.58)$, and $7.32(S D=2.81)$, respectively.

\section{Overview of Qualitative Responses}

Of the sample, $31.4 \%$ expressed their willingness to live longer (group 1), 30.6\% did not (group 2), and 38\% presented no clear positioning (group 3). Explanations for being (un)willing to live were given by $63 \%(n=38)$ of those in the first group and by $78 \%$ ( $n=37$ ) of those in the second group; the other participants did not give any justification for their answers. From the third group $(n=46), 38$ participants referred to aspects related with God; this were the only topic of reference for their answers.

The reference to God appeared in all three groups but with different meanings. Those who reported wanting to live longer asked God to provide them additional time ("Living another month or two is already good, but I put it in God's hands"). Those reporting being unwilling to live longer asked God to take them/asked God for death ("I would like to die, but God gave me this punishment of living so many years, and I must accept it"). Finally, those who did not demonstrate a clear presence/absence of will to live stated that their future was in God's hands ("We do not command anything, only God knows"). Tables 1, 2 present the reasons given by groups 1 and 2, respectively, as well as the number of quotations in each category and illustrative quotations.

In the first group (i.e., those willing to live longer), the most frequent reasons besides those related to God concerned family ( $n=14)$, such as the wish to meet new great-grandchildren or see a grandchild's achievements (e.g., wedding, university graduation). Further reasons were conditionally related to the centenarian's future functioning in the sense that the participants only wanted to live longer if they were in the same condition they were at the time of the interview, without being a burden to others. Three participants reported enjoying life, in the sense that they want to live longer to appreciate the good things of life.

The centenarians in group 2 (i.e., those unwilling to live longer) presented a greater diversity of reasons for their answers. Along with aspects related to God, important reasons included annoyance $(n=14)$, uselessness $(n=6)$, and loss of meaning $(n=5)$. The participants stated that they did not desire to live 
TABLE 2 | Reasons for being unwilling to live longer and the number of quotations for each.

\begin{tabular}{|c|c|}
\hline Category $(n)^{\mathrm{a}}$ & Examples of quotations \\
\hline God (10) & $\begin{array}{l}\text { I would like to die, but God gave me this } \\
\text { punishment for living, and I have to accept } \\
\text { it. }\end{array}$ \\
\hline Annoyance (9) & $\begin{array}{l}\text { Time passes so slowly, especially the } \\
\text { nights; it seems that the day never comes } \\
\text { again. }\end{array}$ \\
\hline Uselessness (6) & $\begin{array}{l}\text { (Because) a person wanting to work and } \\
\text { not being able to [...] is not worthy. }\end{array}$ \\
\hline Loss of meaning (5) & $\begin{array}{l}\text { I often ask myself "What am I still doing } \\
\text { here?" }\end{array}$ \\
\hline $\begin{array}{l}\text { (Social) disconnection and } \\
\text { loneliness (5) }\end{array}$ & $\begin{array}{l}\text { I go to the street to have a coffee }[. . .] \\
\text { people always come, look at me but I } \\
\text { don't know anyone. }\end{array}$ \\
\hline Sense of burden (3) & $\begin{array}{l}\text { I cannot do anything; I am here just to } \\
\text { overwhelm [the others]. }\end{array}$ \\
\hline Dependency (3) & $\begin{array}{l}\text { Because I am getting older, with less } \\
\text { strength, and I'm no longer able to drag } \\
\text { myself. }\end{array}$ \\
\hline (Fear of) suffering (3) & $\begin{array}{l}\text { I wanted to die so I do not have to be here } \\
\text { in suffering. I have a lot of pain. }\end{array}$ \\
\hline Living outside my own home (3) & $\begin{array}{l}\text { I am very scorned here. I didn't need to be } \\
\text { here at the nursing home. }\end{array}$ \\
\hline Loss of family members (1) & $\begin{array}{l}\text { I wish I had already died when my little } \\
\text { children died. }\end{array}$ \\
\hline
\end{tabular}

${ }^{a}$ Frequencies were not mutually exclusive.

longer because "time passes so slowly" and because every day was alike. This reason was related to a feeling of being useless; several participants complained about doing nothing/not being able to work or about the loss of meaning due to lack of purpose in life. Disconnection and loneliness constituted other reasons; some participants felt detached from the place they lived ("I go to the street [...] I don't know anyone anymore") or lonely, especially those who spent long periods of time alone. Dependency, sense of burden, and suffering (or the fear of being in suffering) were referenced each as reasons by three participants and related to situations of lacking functionality and pain. Three participants (who lived in nursing homes) stated that living outside their home was the reason they were unwilling to live longer. Lastly, one participant mentioned the loss of his children as the life event that made him lose all desire to live longer (Table 2).

\section{Factors Associated With Will to Live}

Table 3 presents the relationships between the three groups and sociodemographic characteristics, health status, social functioning, and well-being. Sociodemographic characteristics were not associated with will to live. Regarding health status, pain frequency and SRH were significantly associated with will to live. Group 2 (unwilling to live longer) presented higher pain frequency (50.0\% as often/always) compared to the other groups (22.9\% in group 1 and $27.5 \%$ in group 3 ). Additionally, $58.3 \%$ of the individuals who were willing to live longer expressed having a good, very good, or excellent SRH, while only $27.3 \%$ of individuals unwilling to live longer presented such a positive SRH. Regarding social functioning, having a friend confidant was the only variable associated with will to live. In the group unwilling to live longer, a higher percentage $(87.5 \%)$ did not have any confidant compared to the other two groups $(42.9 \%$ in the group willing to live and $52.6 \%$ in the group with no clear positioning). For well-being, positive VOL was significantly associated with the outcome variable. Group 1 presented higher mean scores of positive VOL (mean $=20)$, including factor 1 $($ mean $=11.1)$ and factor $2($ mean $=8.84)$, compared to the other two groups.

\section{DISCUSSION}

Centenarians are an elite group, significantly exceeding the average life expectancy. This study explored the will to live and associated factors in a sample of these long-lived individuals by considering both quantitative indicators and qualitative data. The number of participants willing and unwilling to live longer was similar (31\%) but lower than those without clear positioning (38\%). Compared with the findings of studies of preferred life expectancy that also considered a non-response group, this was a very high percentage. For instance, in a study of 1,631 younger and middle-aged adults, Bowen and Skirbekk (2017) found that $15.9 \%$ of the sample did not clarify their preferred life expectancy. However, due to the lack of studies similar to the present one, whether the greater percentage was related to the centenarians' characteristics or the methodology of the study cannot be determined. Nevertheless, this group may have represented a stoic mindset in which individuals express a valuation of life per se and "as it comes" with discomfort or unwillingness to reflect about lifetime extension (Lang and Rupprecht, 2019).

Still, the qualitative exploration of this group's answers showed that almost everyone justified their lack of answer/positioning by mentioning God, stating that their remaining time to live was a matter that was not in "their hands" (i.e., one they could not control). This follows the idea that a sense of control through the sacred may come when life seems out of control (Wong et al., 2014). Although a sense of control is recognized as an important source of human life-strength, individuals who accept that declining control over environment comes with aging and focus on their ability to control their own internal states and behaviors demonstrate a more successful adjustment to aging (Hyer et al., 2011). Indeed, this group presented a satisfaction with life score very close to the group reporting willingness to live longer.

Regarding the reference to God, which was also present in the other two groups, religion and spirituality play an important role in the lives of older adults, as they help older people find meaning in later life (Frankl, 1963; Atchley, 2009; Wong et al., 2018) and are thus associated with how long one desires to live (Lang and Rupprecht, 2019). Different studies focusing on the centenarian population have confirmed the positive impact of religion and spirituality in well-being, which may be even more significant since this age group may fail to derive basic resources (Bishop, 2011). Archert et al. (2005) found that 
TABLE 3 | Distribution of sample characteristics by total and will to live groups.

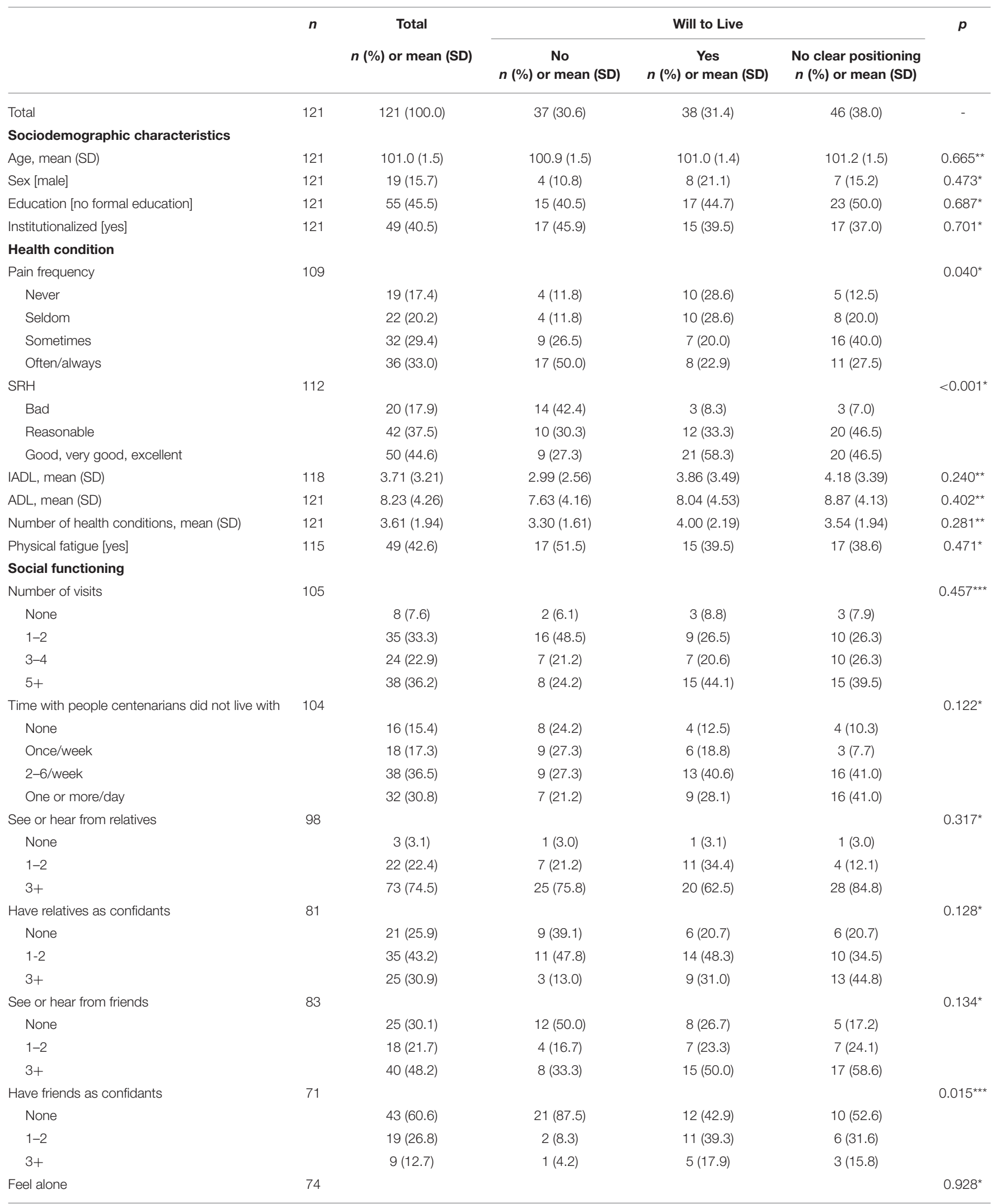




\begin{tabular}{|c|c|c|c|c|c|c|}
\hline & $n$ & $\begin{array}{c}\text { Total } \\
n(\%) \text { or mean (SD) }\end{array}$ & \multicolumn{3}{|c|}{ Will to Live } & $p$ \\
\hline Yes, many times & & $15(20.3)$ & $5(20.8)$ & $4(15.4)$ & $6(25.0)$ & \\
\hline Sometimes & & $22(29.7)$ & $8(33.3)$ & $9(34.6)$ & $5(20.8)$ & \\
\hline Almost never & & $18(24.3)$ & $5(20.8)$ & $7(26.9)$ & $6(25.0)$ & \\
\hline \multicolumn{7}{|l|}{ Well-being } \\
\hline Satisfaction with life, mean (SD) & 78 & $6.54(1.93)$ & $5.79(2.06)$ & $6.93(2.00)$ & $6.81(1.59)$ & $0.072^{\star \star}$ \\
\hline Positive VOL (total), mean (SD) & 81 & $16.7(6.0)$ & $11.1(4.9)$ & $20.0(4.9)$ & $18.2(4.5)$ & $<0.001^{\star \star}$ \\
\hline Positive VOL factor 1 , mean (SD) & 81 & $9.39(3.58)$ & $6.08(3.04)$ & $11.1(2.8)$ & $10.5(2.8)$ & $<0.001^{\star \star}$ \\
\hline Positive VOL factor 2, mean (SD) & 81 & $7.32(2.81)$ & $5.07(2.60)$ & $8.84(2.48)$ & $7.71(2.06)$ & $<0.001^{* \star}$ \\
\hline
\end{tabular}

${ }^{\star}$ Chi-square test; ${ }^{* \star}$ one-way ANOVA; ${ }^{* \star \star}$ Fisher's exact test.

religiosity was one of the major themes that emerged from a qualitative analysis about adaptation and coping in the lives of centenarians; when asked about the most important thing in their lives, $58 \%$ of the respondents mentioned church and/or God. Interestingly, a female centenarian shared a sentence very similar to one of the participants in the present study, arguing that the future is held in God's hands (Archert et al., 2005). Furthermore, Manning et al. (2012) found that centenarians place considerable importance on divine support in their lives. This study found an interconnectedness of spirituality with religion for centenarians; in other words, these two constructs overlap. Through a phenomenological examination of life-satisfaction and compensatory strategies in Jewish-Canadian centenarians, Milevsky (2021) found that compensatory, cultural, and religious processes were imbued into several of the themes, such as "Maintaining connections with family, friends, and God" (p. 101) and "Remaining positive and kind" (p. 104). It is expected to have an intrinsic need to have hope that goes beyond this life and have faith either in something or in someone, which can be religiously oriented or without any religiosity (Saarelainen et al., 2020). But the huge presence of religion in centenarians' discourses found in the present study may echo the importance of church and military in shaping the lives of this older Portuguese generation (Birmingham, 2003), as well as the overall impact of religious beliefs, practices, and culture (Boerner et al., 2019).

The quantitative results of the present study revealed the significant contribution of health (pain frequency and $\mathrm{SRH}$ ), social functioning (friends as confidants), and well-being (positive valuation of life). These findings confirmed that will to live is the summation of individuals' biopsychosociospiritual dimensions (Bornet et al., 2021) and depends on both external (e.g., social networks) and intra-personal factors (e.g., health and self-perceptions; Lawton et al., 1999). No sociodemographic variable was found to be relevant, which agreed with the findings of a scope review on will to live conducted by Bornet et al. (2021). Positive VOL had the strongest significant association with will to live, which was expected. Despite the great importance being attributed to variables like physical and health functionality in longevity and quality of life (Rowe and
Kahn, 1997), some studies have emphasized the importance of psychological functioning and well-being, especially for very old individuals. For instance, a comparison of components in the World Health Organization's (WHO) active aging model by age group ( $<75$ years vs. $\geq 75$ years) revealed the major relevance of the psychological component to the older age group (Paúl et al., 2017). Likewise, the operationalization of the successful aging model (Rowe and Kahn, 1997) in centenarians revealed the importance of subjective appraisals and psychological variables (Araújo et al., 2016).

The fact that the number of health conditions and levels of fatigue and functional capacity presented no significant association with will to live in this study supported the argument that individuals with problems related to physical health and functioning may be able to maintain subjective well-being. This agreed with the paradox of well-being, i.e., reporting experiences of positive psychological functioning despite decline in physical health, as the evidence of resilience in old age (Wiesmann and Hannich, 2014). Interestingly, pain and SRH, the two health factors with a significant impact on will to live, have also been associated with resilience in centenarians (Amaral et al., 2020). Gu and Feng (2018) argued that higher resilience could yield a greater protection for SRH and life satisfaction among centenarians compared with younger elderly groups. Thus, resilience may also be associated with will to live, as identified in younger groups (Bornet et al., 2021). This was supported by the qualitative analysis; aspects related to health, such as dependency, sense of burden, and fear of suffering, were referred to less than uselessness, annoyance, and loss of meaning by centenarians who were unwilling to live longer.

In advanced age, some aspects of purpose in life are more difficult to fulfill, such as having goals for the far future or feeling useful (Pinquart, 2002). This study found that these variables continue to be very important, specifically for (un)willingness to live. Conversely, will to live has strong, direct effects on well-being, including life and aging satisfaction (Jopp et al., 2017). The large influence of positive VOL on will to live meets Lawton et al.'s (1999) assumptions (i.e., years of desired life are mediated by VOL) in an age group in which this issue 
was not studied. Both existential beliefs and perceived control were higher in the group willing to live longer-that is, they represented important aspects for centenarians' reason for living, even under difficult conditions of functional impairment and disease. This confirmed that a "possible mechanism for the potency of VOL as a determinant of Years of Desired Life is the ability of people to adjust their standards for what is acceptable in everyday life in accord with changes in both their personal characteristics and the circumstances under which they live" (Lawton et al., 2001, p. 25).

Social factors also seem to have a contribution to will to live (Bornet et al., 2021), being an important source of meaning in life among older people (Saarelainen et al., 2020). Social relationships and support may be particularly important for centenarians (Boerner et al., 2016). The loss of friends and relatives that is typical in these long-lived individuals can make social contacts even more significant by reducing opportunities for (intra- and intergenerational) relationships (Randall et al., 2010). In the present study, the only social variable significantly associated with will to live was the number of friends as confidants. Thus, support-rather than size-may be the most significant aspect of social networks. Previous studies of the oldest old have shown the importance of having a close friend for independence (Pin et al., 2005) and well-being (Johnson and Barer, 1997). Indeed, maintaining a confidant is suggested as a strategy that centenarians use to compensate for losses and increase wellbeing (Araújo and Ribeiro, 2012). From the qualitative data, (social) disconnection and loneliness emerged as an important motive for losing will to live, as was also the case of feeling like a burden.

This last reason, which is typically referred to in studies on will to live (Bornet et al., 2021) since its related to the high burden of taking care of a person in the end of life, shows the need to acknowledge those who are supporting centenarians. The few studies that investigated will to live and end of life issues in centenarian's caregivers and offspring indicated concerns of family members that they'd become a burden for caregivers and would face the unavailability of family support if they became centenarians (Brandão et al., 2019). The fact that caregivers value this aspect so much, reinforces their potential burdens and needs. If being willing to live at 100 years old depends on the availability of social support, more must be invested in these caregiving offspring who are confronted with their own advanced age and the burdens of their parents' very old age (Eggert et al., 2020).

Despite the richness of this study's findings, some limitations should be considered. The cross-sectional design of the study prevented the ability to determine the direction of the relationships between variables, which could be of particular interest in this topic since willingness to live could be a predictor of well-being. Furthermore, those who shared their opinion (i.e., mostly individuals with mild or no cognitive impairment) represented only a part of the original sample, so these findings should not be generalized to the centenarian population.

\section{CONCLUSION}

The current study added to the literature on will to live by presenting empirical research on an understudied population and focusing on a under-researched topic. A long life is an ambition and desire for many people, but the proportion of individuals who are willing to live longer at 100 years of age is the same as those who do not. Health factors appear to be significant in shaping such will, but social and psychological factors also play a role, which can be observed by the importance given to God and religious meaning and to connectivity. These results provide researchers suggestions for further investigation and highlight the importance of inquiring and understanding very old people's values and views on their will to live and their future wishes, and of creating conditions that promote very old people's meaning in life.

\section{DATA AVAILABILITY STATEMENT}

The datasets presented in this article are not readily available because this study is part of a larger. Requests to access the datasets should be directed to Laetitia Teixeira, laetitiateixeir@gmail.com.

\section{ETHICS STATEMENT}

The study was approved by Portuguese National Data Protection Commission and the participants provided their written informed consent to participate in this study.

\section{AUTHOR CONTRIBUTIONS}

OR, LA, and LT were responsible for the study conception and design. OR supervised data collection and helped write the manuscript. LA wrote the manuscript. LA and OR performed the qualitative analysis. LT performed the quantitative data analysis and helped write the manuscript. RA critically revised the paper for important intellectual content. All authors contributed to the article and approved the submitted version.

\section{FUNDING}

This article was supported by National Funds through Fundação para a Ciência e a Tecnologia (FCT) within the CINTESIS R\&D Unit (reference UIDB/4255/2020).

\section{ACKNOWLEDGMENTS}

The authors would like to thank the guidance of Dr. Daniela Jopp and Dr. Christoph Rott from the Second Heidelberg Centenarian Study (Germany), the support of the study team and the participation of the centenarians and their families. 


\section{REFERENCES}

Amaral, A., Afonso, R., Brandão, D., Teixeira, L., and Ribeiro, O. (2020). Resilience in very advanced ages: a study with centenarians. Int. J. Aging Hum. Dev. 93, 601-618. doi: 10.1177/0091415020926839

Araújo, L., and Ribeiro, O. (2012). Centenários: que redes sociais. Kairós 15, 57-74. doi: 10.23925/2176-901X.2012v15iEspecial11p57-74

Araújo, L., Ribeiro, O., and Paúl, C. (2017). The role of existential beliefs within the relation of centenarians' health and well-being. J. Relig. Health 56, 1111-1122. doi: 10.1007/s10943-016-0297-5

Araújo, L., Ribeiro, O., Teixeira, L., Jopp, D., Rott, C., and Paúl, C. (2015). Measuring attachment to life in old age: the Portuguese version of the Positive Valuation of Life Scale (Positive VOL). Qual. Life Res. 24, 2385-2389. doi: 10.1007/s11136-015-0981-z

Araújo, L., Ribeiro, O., Teixeira, L., and Paúl, C. (2016). Successful aging at 100 years: the relevance of subjectivity and psychological resources. Int. Psychogeriatr. 28, 179-188. doi: 10.1017/S1041610215001167

Archert, S., Brathwaite, F., and Fraser, H. (2005). Centenarians in Barbados: the importance of religiosity in adaptation and coping and life satisfaction in the case of extreme longevity. J. Relig. Spiritual Aging 18, 3-19. doi: 10.1300/J496v18n01_02

Atchley, R. C. (2009). Spirituality and Aging. Maryland: The John Hopkins University Press.

Birmingham, D. (2003). A Concise History of Portugal, 2nd Edn. Cambridge: Cambridge University Press. doi: 10.1017/CBO9781107280212

Bishop, A. (2011). "Spirituality and religiosity connections to mental and physical health among the oldest old," in Understanding Well-Being in the Oldest Old, eds L. Poon and J. Cohen-Mansfield (Cambridge Cambridge: University Press), 227-239. doi: 10.1017/CBO9780511920974.014

Boerner, K., Jopp, D., Kim, K., Butt, A., Ribeiro, O., Araujo, A., et al. (2019). Thinking about the end of life when it is near: a comparison of German and Portuguese centenarians. Res. Aging 41, 65-285. doi: $10.1177 / 0164027518807919$

Boerner, K., Jopp, D., Park, M.-K., and Rott, C. (2016). Whom do centenarians rely on for support? Findings from the second Heidelberg centenarian study. J. Aging Soc. Policy 28, 165-186. doi: 10.1080/08959420.2016.1160708

Bornet, M.-A., Bernard, M., Jaques, C., Truchard, E., Borasio, G., and Jox, R. (2021). Assessing the will to live: A scoping review. J. Pain Symptom Manage. 61, 845-857.e18. doi: 10.1016/j.jpainsymman.2020.09.012

Bowen, C., Christiansen, S., Emelyanova, A., Golubeva, E., Stonawski, M., and Skirbekk, V. (2020). Living too long or dying too soon? Exploring how long young adult university students in four countries want to live. J. Adult Dev. 27, 157-169. doi: 10.1007/s10804-019-09335-y

Bowen, C., and Skirbekk, V. (2017). Old age expectations are related to how long people want to live. Ageing Soc. 37, 1898-1923. doi: $10.1017 /$ S0144686X16000726

Brandão, D., Ribeiro, O., and Jopp, D. (2019). Would I want to reach age 100 ? Perspectives of centenarians' family members on reaching exceptional longevity. J. Fam. Issues 40, 1086-1101. doi: 10.1177/0192513X19833094

Braun, V., and Clarke, V. (2006). Using thematic analysis in psychology. Qual. Res. Psychol. 3, 77-101. doi: 10.1191/1478088706qp063oa

Carmel, S. (2012). Gender differences and the will-to-live in old age. Przeglad Lek. $69,49-53$.

Cheng, A., Leung, Y., and Brodaty, H. (2021). A systematic review of the associations, mediators and moderators of life satisfaction, positive affect and happiness in near-centenarians and centenarians. Aging Ment. Health 1, 1-17. doi: $10.1080 / 13607863.2021 .1891197$

Diener, E., Emmons, R., Larsen, R., and Griffin, S. (1985). The satisfaction with life scale. J. Pers. Assess. 49, 71-75. doi: 10.1207/s15327752jpa4901_13

Eggert, S., Wenzel, A., Suhr, R., Gellert, P., and Drager, D. (2020). Caregiving adult children's perceptions of challenges relating to the end of life of their centenarian parents. Scand. J. Caring Sci. doi: 10.1111/scs. 12921. [Epub ahead of print]

Fillenbaum, G. G., and Smyer, M. A. (1981). The development, validity, and reliability of the OARS multidimensional functional assessment questionnaire. J. Gerontol. 36, 428-434. doi: 10.1093/geronj/36.4.428

Fleming, J., Farquhar, M., CC75C study collaboration, Brayne, C., and Barclay, S. (2016). Death and the oldest old: Attitudes and preferences for end-of-life
care-Qualitative research within a population-based cohort study. PLoS ONE 11:e0150686. doi: 10.1371/journal.pone. 0150686

Frankl, V. E. (1963). Man's Search for Meaning: An Introduction to Logotherapy. Washington, DC: Washington Square Press.

Gu, D., and Feng, Q. (2018). Psychological resilience of Chinese centenarians and its associations with survival and health: a fuzzy set analysis. J. Gerontol. B. Psychol. Sci. Soc. Sci. 73, 880-889. doi: 10.1093/geronb/gbw071

Hsieh, H. F., and Shannon, S. E. (2005). Three approaches to qualitative content analysis. Qual. Health Res. 15, 1277-1288. doi: 10.1177/1049732305276687

Huohvanainen, E. A., Strandberg, T. E., Pitkala, K. H., Karppinen, H., and Tilvis, R. S. (2012). Do you wish to live to the age of 100 ? A survey of older men. J. Am. Geriatr. Soc. 60, 1983-1984. doi: 10.1111/j.1532-5415.2012.04174.x

Hyer, L., Yeager, C., and Scott, C. (2011). "Late-life psychotherapy: challenges and opportunities to enhance well-being in the oldest old," in Understanding WellBeing in the Oldest Old, eds L. Poon, and J. Cohen-Mansfield (Cambridge: Cambridge University Press), 332-363. doi: 10.1017/СВO9780511920974.019

Johnson, C., and Barer, B. (1997). Life Beyond 85 Years: The Aura of Survivorship. New York, NY: Springer.

Jopp, D., Meystre, C., and Lampraki, C. (2017). Meaning in life and will to live as predictors of well-being in centenarians. Innov. Aging 1(Suppl. 1):1294. doi: 10.1093/geroni/igx004.4729

Jopp, D., and Rott, C. (2006). Adaptation in very old age: exploring the role of resources, beliefs, and attitudes for centenarians' happiness. Psychol. Aging 21, 266-280. doi: 10.1037/0882-7974.21.2.266

Karppinen, H., Laakkonen, M.-L., Strandberg, T., Huohvanainen, E., and Pitkala, K. (2016). Do you want to live to be 100? Answers from older people. Age Ageing 45, 43-549. doi: 10.1093/ageing/afw059

Kato, K., Zweig, R., Schechter, C., Barzilai, N., and Atzmon, G. (2015). Positive attitude toward life, emotional expression, self-rated health, and depressive symptoms among centenarians and near-centenarians. Aging Ment. Health 20, 930-939. doi: 10.1080/13607863.2015.1056770

Lang, F., and Rupprecht, F. (2019). Motivation for longevity across the life span: an emerging issue. Innov. Aging 3, 1-11. doi: 10.1093/geroni/igz014

Lawton, M. P., Moss, M., Hoffman, C., Grant, R., Have, T., and Kleban, M. (1999). Health, valuation of life, and wish to live. Gerontologist 39, 406-416. doi: $10.1093 /$ geront $/ 39.4 .406$

Lawton, M. P., Moss, M., Hoffman, C., Kleban, M., Ruckdeschel, K., and Winter, L. (2001). Valuation of life: a concept and a scale. Aging Ment. Health 13, 3-31. doi: $10.1177 / 089826430101300101$

Lubben, J. (1988). Assessing social networks among elderly populations. Fam. Community Health 11, 42-52. doi: 10.1097/00003727-198811000-00008

Mackowicz, J., and Wnek-Gozdek, J. (2016). The process of (non) ageing in the perception of Polish centenarians. Educ. Gerontol. 43, 101-111. doi: 10.1080/03601277.2016.1263926

Manning, L., Leek, J., and Radina, E. (2012). Making sense of extreme longevity: explorations into the spiritual lives of centenarians. J. Relig. Spiritual Aging 24, 345-359. doi: 10.1080/15528030.2012.706737

Mathers, C., Stevens, G., Ties, B., White, R., and Tobias, M. (2015). Causes of international increases in older age life expectancy. Lancet 385, 7-13. doi: 10.1016/S0140-6736(14)60569-9

Milevsky, A. (2021). The centenarian transition: a phenomenological examination of life-satisfaction and compensatory strategies in aging Jewish-Canadians. Ment. Health Relig. Cult. 24, 97-110. doi: 10.1080/13674676.2021.1882976

Paúl, C., Teixeira, L., and Ribeiro, O. (2017). Active aging in very old age and the relevance of psychological aspects. Front. Med. 4:181. doi: 10.3389/fmed.2017.00181

Pin, S., Guilley, E., Spini, D., and Lalive d'Epinay, C. (2005). The impact of social relationships on the maintenance of independence in advanced old age: findings of a Swiss longitudinal study. Zeitschrift für Gerontologie und Geriatrie 38, 203-209. doi: 10.1007/s00391-005-0250-9

Pinquart, M. (2002). Creating and maintaining purpose in life in old age: a meta-analysis. Ageing Int. 27, 90-114. doi: 10.1007/s12126-002-1004-2

Randall, G., Martin, P., McDonald, M., and Poon, L. (2010). Social resources and longevity: findings from the Georgia centenarian study. Gerontology 56, 106-111. doi: 10.1159/000272026

Ribeiro, O., Araújo, L., Teixeira, L., Brandão, D., Duarte, N., and Paúl, C. (2015). "Oporto centenarian study," in Encyclopedia of Geropsychology, ed N. Pachana (Singapore: Springer-Verlag), 1-7. doi: 10.1007/978-981-287-080-3_141-1 
Rowe, J., and Kahn, R. (1997). Successful aging. Gerontologist 37, 433-440. doi: 10.1093/geront/37.4.433

Saarelainen, S.-M., Mäki-Petäjä-Leinonen, A., and Päyhiä, R. (2020). Relational aspects of meaning in life among older people - a group-interview gerontechnology study. Ageing Soc. 1-19. doi: 10.1017/S0144686X20001300

Sachdev, P., Levitan, C., and Crawford, J. (2012). Methodological issues in centenarian research: pitfalls and challenges. Asian J. Gerontol. Geriatr. $7,44-48$.

Serra, V., Watson, J., Sinclair, D., and Kneale, D. (2011). Living Beyond 100: A Report on Centenarians. London: International Longevity Centre.

Shah, A., Zarate-Escudero, S., Bhat, R., De Leo, D., and Erlangsen, A. (2014). Suicide in centenarians: the international landscape. Int. Psychogeriatr. 26, 1703-1708. doi: 10.1017/S1041610214001112

Teixeira, L., Araújo, L., Paul, C., and Ribeiro, O. (2020). Centenarians: An European Overview. New York, NY: Springer. doi: 10.1007/978-3-030-52090-8

Van Wijngaarden, E., Leget, C., and Goossensen, A. (2015). Ready to give up on life: the lived experience of elderly people who feel life is completed and no longer worth living. Soc. Sci. Med. 138:257e264. doi: 10.1016/j.socscimed.2015. 05.015

Wiesmann, U., and Hannich, H. J. (2014). A salutogenic analysis of the well-being paradox in older age. J. Happiness Stud. 15, 339-355. doi: 10.1007/s10902-013-9425-Z

Wong, S., Pargament, K., and Faigin, C. (2018). "Sustained by the sacred: religious and spiritual factors for resilience in adulthood and aging," in Resilience in Aging: Concepts, Research, and Outcomes, eds N. Resnick,
L. Gwyther, and K. Roberto (New York, NY: Springer), 191-214 doi: 10.1007/978-3-030-04555-5_10

Wong, W.-C., Lau, H.-P., Kwok, C.-F., Leung, Y.-M., Chan, M.-Y., Chan, W.M., et al. (2014). The well-being of community-dwelling near-centenarians and centenarians in Hong Kong: a qualitative study. BMC Geriatr. 14:63. doi: $10.1186 / 1471-2318-14-63$

Conflict of Interest: The authors declare that the research was conducted in the absence of any commercial or financial relationships that could be construed as a potential conflict of interest.

Publisher's Note: All claims expressed in this article are solely those of the authors and do not necessarily represent those of their affiliated organizations, or those of the publisher, the editors and the reviewers. Any product that may be evaluated in this article, or claim that may be made by its manufacturer, is not guaranteed or endorsed by the publisher.

Copyright (c) 2021 Araújo, Teixeira, Afonso and Ribeiro. This is an open-access article distributed under the terms of the Creative Commons Attribution License (CC $B Y)$. The use, distribution or reproduction in other forums is permitted, provided the original author(s) and the copyright owner(s) are credited and that the original publication in this journal is cited, in accordance with accepted academic practice. No use, distribution or reproduction is permitted which does not comply with these terms. 